Borneo Journal of Sciences and Technology, Volume (2), Issue (1), Pages: 58-62

DOI: https://doi.org/10.35370/bjost.2020.2.1-10

e-ISSN: 2672-7439

(C) 2018, UCTS Publisher.

Submitted: $2^{\text {nd }}$ October $2019 \quad$ Accepted: $4^{\text {th }}$ December $2019 \quad$ Published: $31^{\text {th }}$ January 2020

\title{
Analysis of Phytochemical Constituents of Garlic (Allium sativum L.) Against Clinical Pathogens
}

\author{
Nur Hidayah Abdul Talib, and Sitti Fatimah Mhd Ramle \\ Faculty of Bioengineering and Technology, Universiti Malaysia Kelantan (UMK), Jeli Campus, 17600 \\ Jeli, Kelantan, Malaysia
}

\begin{abstract}
Garlic which is scientifically known as Allium sativum L. is one of those herbs that give a lot of beneficial medicinal properties in curing many diseases. In this study, the phytochemical constituents that presence in garlic has been analysed and studied about their effectiveness on the antibacterial activities. The antibacterial potency of aqueous and ethanol extracts of garlic was determined in-vitro against two bacterial isolates which are Escherichia coli and Staphylococcus aureus by agar disc diffusion method. The results of the analysis of antimicrobial activities of garlic extracts showed that ethanol extract is more susceptible in inhibiting the growth of bacteria isolated but aqueous extracts is less effective in inhibiting the growth of bacteria. The minimum inhibition concentration also proved that ethanol extract was the lowest at $1.0 \mathrm{mg} / \mathrm{ml}$ against both isolated bacteria. The natural herbs such as garlic possess effective antibacterial properties against clinical pathogens which are bacterium, viruses or other microorganisms that cause diseases that have been cultured in the laboratory for medical purposes. The benefits of this herb can be used for the development of drug resistant microbial diseases with necessary further evaluation.
\end{abstract}

Keywords: Herbs, garlic, antimicrobial, phytochemical, extracts.

\section{INTRODUCTION}

Allium sativum $L$. which is known as garlic is related to onion genus. It has a powerful pungent smell and taste that makes it truly the mighty out of herbs and spices [1]. Allicin that presents in garlic is also a powerful antibiotic and antifungal compound (phytoncide). Alliinase enzyme in garlic will act upon the reaction of the alliin of the mesophyll cells [2].

Garlic can lead to harmful effects if it is taken excessively where it can cause blood thinning, heartburn and hyphema [3]. Phytochemicals are naturally occurring in medicinal plants, leaves, vegetables and roots that have defence mechanism and protect from various diseases [4]. Antimicrobial activity refers to the process of killing/inhibiting the diseasecausing microbes.

Garlic extracts were studied on its antibacterial activities against two types of clinical pathogens using a broth microdilution method and disk diffusion method. A microdilution technique using commercially available media and materials was developed and used to determine minimal inhibitory concentrations (MICs) [5]. Meanwhile, the disk diffusion method was based on the principle that antibiotic-impregnated disk, the inoculated test bacterium was placed on agar previously, pick-up moisture and the garlic extracts are diffused radially outward through the agar medium producing an antibiotic concentration gradient [6]. A clear zone was formed around an antibiotic disk after incubation if the garlic extracts able to inhibit bacterial growth.

The main objectives of this study are to extract Allium sativum L. (garlic) in different solutions which are aqueous extracts from distilled water and Ethanol extracts from ethanol solvent. Next is to identify phytochemical compounds present in the extracts of garlic (Allium sativum L.) and also to determine the antibacterial activities from Allium sativum L. (garlic) extracts against different types of clinical pathogens.

\section{MATERIALS AND METHODS}

\section{Plant Procurement}

Garlic cloves were purchased from the near market in Jeli. $40 \mathrm{~g}$ of garlic cloves were skinned and then washed using tap water and then rinsed with distilled water. The washed garlic cloves are air dried and then crushed using mortar and pestle. The crushed garlic was ready for the preparation of aqueous and solvent extracts.

Corresponding Author: Sitti Fatimah Mhd Ramle, Faculty of Bioengineering and Technology, Universiti Malaysia Kelantan (UMK), Jeli Campus, 17600 Jeli, Kelantan, Malaysia, fatimah.m@umk.edu.my 


\section{Extraction Process}

Extraction process was prepared using a Soxhlet apparatus. Crushed garlic extracted for 4-6 hours or until it becomes concentrated in a Soxhlet apparatus successively with $250 \mathrm{ml}$ of solvents filled in the roundbottom flask at the bottom of the extractor [7]. The concentration and the mass of yield of the extract then calculated and stored in a bottle at $-2{ }^{\circ} \mathrm{C}$ until the analysis process.

\section{Phytochemical Test}

Phytochemical components were analysed using Gas chromatography-mass spectrometry (GC-MS) and Fourier-Transform Infrared Spectroscopy (FTIR) Analysis method wherein GC-MS, garlic extracts that have been processed in rotary evaporator and diluted with absolute ethanol were vapourised and injected onto the head of the chromatographic column [8] and the results were generated automatically while in FTIRAnalysis.

\section{Antibacterial Test Preparation}

The test bacteria for the antibacteria test were clinically isolated of gram-positive bacteria (Staphylococcus cereus) and gram-negative bacteria (Escherichia coli). Luria bertani Agar (Lb Agar) was dissolved in $500 \mathrm{ml}$ of distilled water. The dissolved medium was autoclaved at $15 \mathrm{lbs}$ pressure at $121^{\circ} \mathrm{C}$ for 15 minutes ( $\mathrm{pH}$ 7.3) [9]. The autoclaved medium then cooled, mixed well and poured into Petri dish.

Four different concentrations of the aqueous and ethanol extracts were prepared for the sensitivity testing: $1.0 \mathrm{mg} / \mathrm{ml}, 3.0 \mathrm{mg} / \mathrm{ml}, 6.0 \mathrm{mg} / \mathrm{ml}$ and 9.0 $\mathrm{mg} / \mathrm{ml}$ respectively and placed in sterile bottles. Subsequently, sterile discs each were aseptically placed in labelled bottles as well as the Dimethyl Sulphoxide (DMSO) as the negative control and Ascorbic Acid as a positive control.

The $6 \mathrm{~mm}$ (diameter) discs were prepared from Whatman No.1 filter paper. Discs were sterilized by autoclave at $12{ }^{\circ} \mathrm{C}$. Paper discs impregnated with different concentration of garlic extracts were placed on the surface of the Luria bertani Agar (Lb Agar) medium inoculated with target organisms. The plates then incubated and the zones of inhibition around each disc were measured.

Antibacterial activities of garlic were carried out by a disc-diffusion method using Kirby-Bauer technique [9]. All the bacterial strains were maintained on Luria bertani Agar (Lb Agar). Pure culture from the plate was inoculated using a sterile wire loop, 3-5 wellisolated colonies of the test organisms were touched and emulsified into about $3 \mathrm{~mL}$ of physiological saline.
The turbidity of the suspension of test organisms was compared and adjusted with 0.5 Mcfarland turbidity standard [8]. Using cotton buds, the test organisms were inoculated onto sterile prepared Lb Agar. The inoculated plates then allowed staying for about 3-5 minutes for the surface media to air dry. The prepared discs of 4 different concentrations, Dimethyl Sulphoxide (DMSO) and Ascorbic Acid were placed on the inoculated agar media. Each paper discs was labelled with $\mathrm{A}, \mathrm{B}, \mathrm{C}, \mathrm{D}, \mathrm{E}$ and $\mathrm{F}$ to indicate the different concentrations of $1.0 \mathrm{mg} / \mathrm{ml}, 3.0 \mathrm{mg} / \mathrm{ml}, 6.0$ $\mathrm{mg} / \mathrm{ml}, \quad 9.0 \mathrm{mg} / \mathrm{ml}$, DMSO and Ascorbic Acid respectively. Within 30 minutes of applications, the plates were inverted and incubated aerobically at $37^{\circ} \mathrm{C}$ for $24 \mathrm{~h} \mathrm{[10].}$

After overnight incubation, the plates were observed for the growth of the test organisms and the inhibition zone was measured using a plastic ruler in $\mathrm{cm}$.

As for the Minimum Inhibition Concentration (MIC) test, a few single colonies from test organisms were obtained and mixed with Lb broth in 20 test tubes. After overnight of incubation, Lb broth was added with appropriate dilution series of garlic extracts to test tubes. Nutrient broth with the inoculums only was used as growth control. All the test tubes were incubated for overnight and then the growth of cultures was checked. This test was to determine the lowest concentration of garlic extracts that able to inhibit the growth of microbes. The MIC was taken as the lowest concentration that prevented visible growth.

\section{RESULTS AND DISCUSSION}

\section{Phytochemical analysis on FTIR and GCMS}

In Figure 1 and 2 represents the functional groups that present in aqueous and ethanol extract respectively.

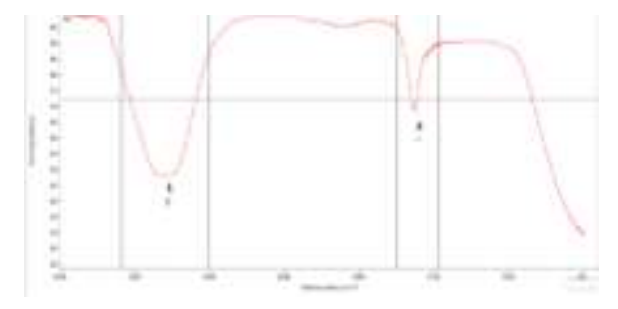

Figure 1: FTIR peaks for the aqueous extract 


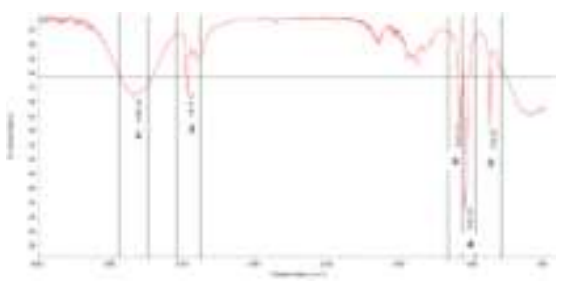

Figure 2: FTIR peaks for the ethanol extract

Based on spectral interpretation in Figure 1, peak 1 gave the compound of Acetamide while peak 2 gave the compound of secondary amide. Acetamide is soluble in water and slightly soluble in ether. Acetamide is combustible and when heated to decomposition, it emits toxic fumes of oxides of nitrogen [11].

In Figure 2, the functional group that presence in ethanol extracts is aliphatic amide groups, alcohol, phenols and aliphatic group. The spectral interpretation gives that peak 1 represents as Acetamide, the same compound that present in aqueous extract. Peak 2 gives the aliphatic groups. To be more specific it portrays the present of $\mathrm{CH}_{3}$ stretching absorptions which the vibration occurs at $2975-2950 \mathrm{~cm}^{-1}$. Aliphatic groups are found in many compounds that the infrared spectroscopic is likely to encounter [12]. For the peak 3, 4 and 5, they represent the alcohol functional groups along with the phenols. Alcohol are compounds which contain the hydroxyl (-OH) group [13].

The phytochemical constituents that have been detected in aqueous and ethanol extracts have been shown in Table 1.

Table 1: Chemical compounds present in aqueous and ethanolic extracts by GCMS

\begin{tabular}{lcc}
\hline Chemical Compound & $\begin{array}{c}\text { Aqueous } \\
\text { Extract }\end{array}$ & $\begin{array}{c}\text { Ethanol } \\
\text { Extract }\end{array}$ \\
\hline Benzoic acid, ethyl ester & Yes & Yes
\end{tabular}

Phenol, 2,2'-methylenebis[6-(1,1dimethylethyl)-4-methyl-

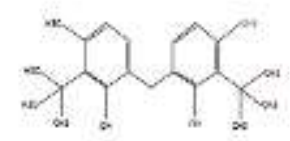

Yes $\quad$ Yes

Beta.-1,5-O-Dibenzoylribofuranose

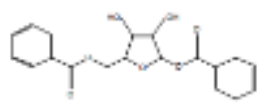

No $\quad$ Yes

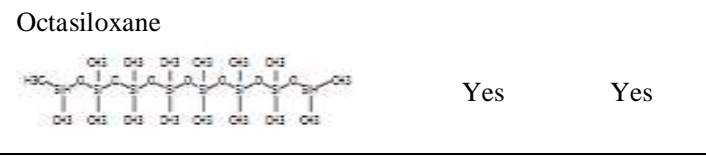

As observed, garlic contains a lot of phytochemical compounds and functional groups that highly have curative properties such as aliphatic amide groups, alcohol functional groups and phenol [12].The ethanolic extract is more potent than the aqueous extracts. In ethanol extract compund Beta.-1, 5-ODibenzoyl-ribofuranose are presence which is, this compound able to reduce inflammatory.

\section{Antibacterial analysis}

Based on the results of the diameter of inhibition the zone obtained, it can be clearly seen that there were no differences in antimicrobial activities for aqueous extract on both Escherichia coli and Staphylococcus aureus bacteria. The results of the diameter zone of inhibition were shown in Table 2. Data were expressed as mean \pm standard deviation to determine whether there was a significant difference between aqueous and ethanol extract used and also between the lengths of inhibition.

The results obtained shows that aqueous extracts really does not have any effect on the growth of both bacteria. This obviously proved the prevised results [14], mentioned that distilled water could not extract phytochemical components that able to inhibit the growth of Escherichia coli and Staphylococcus aureus.

Meanwhile, Table 2 shows the results of the diameter of the zone of inhibition for the antimicrobial activities of Ethanol extracts against Escherichia coli and Staphylococcus aureus. There were differences between the diameter zones of inhibition on different concentration of ethanol extracts towards the growth of both bacteria. Data were expressed as mean \pm standard deviation to determine whether there was a significant difference between aqueous and ethanol extract used and also between the lengths of inhibition.

The results showed that on the $1.0 \mathrm{mg} / \mathrm{ml}$ concentration of the ethanol extract, the mean of diameter zone of inhibition and standard deviation for Escherichia coli and Staphylococcus aureus was $(0.503$ $\pm 0.015)$ and $(0.503 \pm 0.006)$ respectively, on $3.0 \mathrm{mg} / \mathrm{ml}$ concentration Staphylococcus aureus had the larger diameter zone of inhibition than Escherichia coli which were $(1.217 \pm 0.012)$ and $(0.813 \pm 0.015)$ respectively. As for the $6.0 \mathrm{mg} / \mathrm{ml}$ concentration of garlic Ethanol extract, the diameter zone of inhibition in Escherichia coli was $(1.120 \pm 0.017)$ while Staphylococcus aureus had $(1.100 \pm 0.010)$. For $9.0 \mathrm{mg} / \mathrm{ml}$ concentration, the diameter zone of inhibition for Escherichia coli is larger than Staphylococcus aureus which was (1.203 \pm 
$0.015)$ and $(1.110 \pm 0.010)$ respectively. For the ascorbic acid, the diameter zone of inhibition for Escherichia coli and Staphylococcus aureus were $(0.713 \pm 0.015)$ and $(0.513 \pm 0.015)$ respectively while the dimethyl sulphoxide (DMSO) had the lowest diameter zone of inhibition for both Escherichia coli and Staphylococcus aureus which was $(0.400 \pm 0.010)$ and $90.600 \pm 0.010$ ) respectively.
The results obtained show that ethanol extract was proven to be one of the best antibacterial resources. This is because ethanol extract showed high positivity of diameter zone of inhibition in inhibiting the growth of both bacteria.

Table 2: Inhibition zone for antimicrobial activity of aqueous extracts and ethanol extracts against Escherichia coli and Staphylococcus aureus.

\begin{tabular}{|c|c|c|c|c|c|}
\hline \multirow{3}{*}{ Type } & \multirow{3}{*}{ Molarity (mg/ml) } & \multicolumn{4}{|c|}{ Diameter zone of inhibition $(\mathrm{cm})$} \\
\hline & & \multicolumn{2}{|c|}{ Escherichia coli } & \multicolumn{2}{|c|}{ Staphylococcus aureus } \\
\hline & & $\begin{array}{l}\text { Aqueous } \\
\text { Extracts }\end{array}$ & $\begin{array}{l}\text { Ethanol } \\
\text { Extracts }\end{array}$ & $\begin{array}{l}\text { Aqueous } \\
\text { Extracts }\end{array}$ & $\begin{array}{l}\text { Ethanol } \\
\text { Extracts }\end{array}$ \\
\hline A & 1.0 & $0.0 \pm 0.0$ & $0.503 \pm 0.015$ & $0.0 \pm 0.0$ & $0.503 \pm 0.006$ \\
\hline B & 3.0 & $0.0 \pm 0.0$ & $0.813 \pm 0.015$ & $0.0 \pm 0.0$ & $1.217 \pm 0.012$ \\
\hline $\mathrm{C}$ & 6.0 & $0.0 \pm 0.0$ & $1.120 \pm 0.017$ & $0.0 \pm 0.0$ & $1.100 \pm 0.010$ \\
\hline $\mathrm{D}$ & 9.0 & $0.0 \pm 0.0$ & $1.203 \pm 0.015$ & $0.0 \pm 0.0$ & $1.110 \pm 0.010$ \\
\hline $\mathrm{E}$ & Ascorbic acid & $0.0 \pm 0.0$ & $0.713 \pm 0.015$ & $0.0 \pm 0.0$ & $0.513 \pm 0.015$ \\
\hline $\mathrm{F}$ & Dimethyl sulphoxide (DMSO) & $0.0 \pm 0.0$ & $0.400 \pm 0.010$ & $0.0 \pm 0.0$ & $0.600 \pm 0.010$ \\
\hline
\end{tabular}

$n=3$

\section{CONCLUSION}

To conclude this research, the antimicrobial properties of garlic which have been extracted using two different solvents which are distilled water and ethanol are being proven to inhibit the growth of the clinical pathogens by antimicrobial testing. Thus this also revealing the presence of phytochemical constituents in the garlic itself that able to fight against bacteria such as beta.-1, 5-O-Dibenzoyl-ribofuranose that presence in ethanol extract that able to reduce inflammatory. Ethanol garlic extracts also proved that it can be the best extract that have antimicrobial properties as it able to inhibit the growth of Escherichia coli and Staphylococcus aureus even with the lowest extract concentration as proved in Minimum Inhibition Concentration (MIC) test. The results also portrayed the folkloric use of this plant in treating microbial infection and showed that garlic could be more exploited for new potent antimicrobial agents.

Further research on the phytochemical constituents isolation and purification of the bioactive compounds of garlic is recommended as it could lead to better development of many other more effective substances that can be used to treat other infectious diseases and perhaps also able to inhibit cancer's virus.

Also, there is a need for providing new automated instruments such machining to measure the Minimum Inhibition Concentration (MIC) in such correct manner and correctly that could provide faster results and also save time. To accomplish this, it will likely be necessary to explore different methodological approaches for detection of bacterial growth.

\section{ACKNOWLEDGMENT}

It is a great pleasure to address people who helped me throughout this project to enhance my knowledge and practical skills especially in the research area of herb plants and analysing its phytochemical constituents that able to react towards the antimicrobial activities. My gratitude is extended to people around me that always helps me in this research from beginning till the end, especially to my supervisor who is Dr. Sitti Fatimah Mhd Ramle that always help me throughout this project by giving me advises, knowledges and convincing me to do better in my research. Not to forget to my parents Abdul Mutalib Bin Maidin and Hazni Binti Seman 
which always give me courages, moral and financial support in order to success in this research. My fellow undergraduate students should also be recognized for their support especially to my close friends who always be there for me and giving me support and courage me to do my best for this project. Finally, I would like to thanks En. Mohd Afifi, our lab assistant, that always prepared everything that I need while doing my research. Without his help, this research would never be done within the time that allocated. I hope that this research project able to give me some outstanding knowledge and experiences so that I can use it in the future for a better well development in myself.

\section{REFERENCES}

[1] Amagase, H. (2006). Clarifying the real bioactive constituents of garlic. The Journal of nutrition, 136(3), 716S-725S.

[2] Ankri, S., \& Mirelman, D. (1999). Antimicrobial properties of allicin from garlic. Microbes and infection, 1(2), 125-129.

[3] Block, E. (2010). Garlic and other alliums: the lore and the science: Royal society of Chemistry.

[4] Borek, C. (2001). Antioxidant Health Effects of Aged Garlic Extract. Retrieved from https://academic.oup.com/jn/article/131/3/1010S/4 687113

[5] Rotilie, C. A., Fass, R. J., Prior, R. B., \& Perkins, R. L. (1975). Microdilution technique for antimicrobial susceptibility testing of anaerobic bacteria. Antimicrobial Agents and Chemotherapy, 7(3), 311-315.

[6] Tendencia, E. A. (2004). . Disk diffusion method Laboratory manual of standardized methods for antimicrobial sensitivity tests for bacteria isolated from aquatic animals and environment (pp. 1329): Aquaculture Department, Southeast Asian Fisheries Development Center.

[7] Azmir, J., Zaidul, I., Rahman, M., Sharif, K., Mohamed, A., Sahena, F., Omar, A. (2013). Techniques for extraction of bioactive compounds from plant materials: a review. Journal of food engineering, 117(4), 426-436.

[8] Arunkumar, S., \& Muthuselvam, M. (2009). Analysis of phytochemical constituents and antimicrobial activities of Aloe vera L. against clinical pathogens. World Journal of Agricultural Sciences, 5(5), 572-576.

[9] Martin, T., \& Lewis, M. (1998). MUELLER HINTON AGAR.

[10] Bauer, A., Kirby, W., Sherris, J. C., \& Turck, M. (1966). Antibiotic susceptibility testing by a standardized single disk method. American journal of clinical pathology, 45(4), 493.
[11] Mustapha, Y., \& Bala, M. (2007). Antimicrobial activ ity of leaf extracts of Pavetta crassipes (hutch) against some respiratory tract pathogens. Science World Journal, 2(2).

[12] Klebe, J., Finkbeiner, H., \& White, D. (1966). Silylations with bis (trimethylsilyl) acetamide, a highly reactive silyl donor. Journal of the American Chemical Society, 88(14), 3390-3395.

[13] Rahman, M. S. (2007). Allicin and other functional active components in garlic: health benefits and bioavailability. International Journal of Food Properties, 10(2), 245-268.

[14] Grosvenor, P. W., Supriono, A., \& Gray, D. O. (1995). Medicinal plants from Riau Province, Sumatra, Indonesia. Part 2: antibacterial and antifungal activity. Journal of ethnopharmacology, 45(2), 97-111. 